long-standing renal disease. J. J. McPhaul and colleagues ${ }^{4}$ described the development of autonomous hyperparathyroidism after restoration of renal function by a transplant. After transplantation there was marked hypophosphataemia, phosphaturia, hypercalciuria, and hypercalcaemia. Patients with this syndrome may require removal of the parathyroid glands to prevent formation of stones and decalcification of the bones.

J. F. Bravo and colleagues ${ }^{5}$ have reviewed 60 long-term surviving patients with renal transplants, the mean follow-up being 491 days from operation. Of these patients $38 \%$ had one or more clinical signs of connective-tissue disorder, apart from muscle weakness, skin diseases, osteoporosis, or neuropathy. Five patients suffered from avascular necrosis of the bone, five from synovitis, thirteen from arthralgia, and ten from diffuse musculo-skeletal pain. Anti-gammaglobulin activity against human globulin was found between the second and twenty-eighth weeks after operation in $93 \%$ of cases regardless of the presence or absence of rheumatic disorders. Antibodies to deoxyribonucleic acid and ribonucleic acid were found in $40 \%$ and $28 \%$ respectively. These workers were unable to detect antibodies to specific constituents in synovial membranes, skeletal muscle, blood vessels, liver, or kidney. Determination of plasma lipids showed fluctuating abnormalities in free and esterified cholesterol, phospholipid, triglycerides, non-esterified fatty acids, and total lipid levels. The synovial fluid consistently showed both intracellular and extracellular refractile, oval, lipid-staining particles varying from less than 1 to over $25 \mu$ in diameter. Bravo and colleagues suggest that the aberrations of lipid metabolism may be secondary to corticosteroid therapy. The very high incidence of the rheumatoid factor in the serum in patients with transplants is of interest, though the mode of production of these antibodies is at present unknown. Humoral antibodies were not found in transplants between twins.

It would seem likely from the work of Bravo and colleagues that ail patients with renal homografts from donors other than twins would eventually develop rheumatoid factor in the serum, but there was no apparent relationship of the appearance of the rheumatoid factor to the pathogenesis of the connective tissue disorders, since the activity appeared regardless of the presence or absence of rheumatic complaints. The severity of rheumatic disturbances was not related to variations in dosages of immunosuppressive drugs. However, J. P. Jones and colleagues ${ }^{6}$ found evidence of fat emboli after rapid reduction of corticosteroid therapy, and fat embolism could be a cause of avascular necrosis of bone.

It is most important that evidence of muscular and skeletal disorders after kidney transplantation should be sought continuously, since early treatment may prevent disastrous consequences, particularly in hyperparathyroidism, when surgery can be entirely effective. There would seem to be a need for caution in suddenly changing corticosteroid doses, and no patient should be kept on high doses longer than is absolutely necessary. If good transplant function can be maintained, the pseudogout arthropathy will not develop.

\footnotetext{
' Calne, R. Y., Loughridge, L., MacGillivray, J. B., and Swales, J. D., Brit. med. F., 1966, 2, 1345 .

${ }^{2}$ McCarty, D. J., jun., Kohn, N. N., and Faires, J. S., Ann. intern. Med. 1962, 56, 7i1.

s Caner, J. E. Z., and Decker, J. L., Amer. F. Med., 1964, 36, 571 - McPhaui, J. J., McIntosh, D. A., Hammond, W.' S., and Park, O. K.,
New Engl. f. Med., 1964, 271, 1342 .

- Bravo, J. F., Herman, J. H., and Smyth, C. J., Ann. intern. Med., $1967,66,87$. - Jones, J. P., jun., Engleman, E. P., and Najarian, J. S., New Engl. F.
Med., 1965, 273, 1453 .
}

\section{Dangers of Squint}

The harmful effects that a squint may have on visual function are not always realized, so that delay in diagnosis, and hence of treatment, is of more frequent occurrence than it should be. The condition is fairly common in children. In fact the clinical study carried out in Manchester and Salford by Drs. A. M. Adelstein and John Scully reported at page 334 of the B.M.F. this week showed that over $4 \%$ of 6 -year-old children had it.

The most serious sequel of untreated squint is amblyopia of the affected eye due to suppression of part of the vision, and it may eventually go on to loss of useful sight in that eye. It is by this process that a child with a squint may overcome the diplopia and confusion which tends to occur when the eyes are constantly looking in different directions. On the other hand a child with a squint may attempt to co-ordinate the function of both eyes by using the fovea centralis of the fixing eye in conjunction with an eccentric point on the retina of the squinting eye. This may operate only when both eyes are open, the squinting eye rapidly resuming foveal fixation if the other eye is covered. It is known as " anomalous retinal correspondence." However, if this abnormal association between the two eyes becomes more stable, the squinting eye may still tend to view a fixation object eccentrically in spite of the other eye being occluded, though the fovea maintains its normal directional value. Such eccentricity of viewing may later give way to "eccentric fixation," in which the eccentric point of fixation becomes relatively stabilized and assumes the principal visual direction of that eye. Eccentricity of fixation is in most cases associated with considerable amblyopia in the squinting eye, and prolonged treatment is usually required to overcome it. It is only in a squint freely alternating from eye to eye or an intermittent squint that really good vision is retained in each eye.

Statistical evidence in Adelstein and Scully's paper shows that the percentage of children with non-central viewing increases as the interval between onset of squint and its diagnosis (and effective treatment) increases. Furthermore it is most frequent in those children who start squinting early in life and less frequent when the squint starts later. This emphasizes the need to refer a doubtful case of squint immediately to an ophthalmologist, so that early treatment can be undertaken. Though a squint of large degree is more likely to attract attention than one of small degree, the adverse affect on visual function may be just as serious in the latter. Every clinician should be familiar with the method of diagnosis of squint by means of the cover test. ${ }^{1}$

Adelstein and Scully have also shown that the longer the interval of time between onset of squint and diagnosis the greater the percentage of children showing non-central viewing. Non-central viewing was most frequent in those who developed a squint at an early age, and the frequency decreased progressively as the age of onset increased, but the trend of decrease was not shown in the group of cases showing the longest interval of time between onset and diagnosis. They also found that a difference in refractive power between the two eyes of two or more dioptres predisposed towards eccentric viewing, and that it was proportionately slightly more frequent in boys than in girls. Furthermore, there was also a tendency for the onset of squint to be commonest in the winter months, with a peak in January.

Wybar, K., in Child Care, p. 223. 1966. British Medical Association, London. 
Although in Manchester and Salford the percentage of cases of squint diagnosed within a year of its onset was about $80-90 \%$ in children who began to squint between the ages of 2 and 6 , it was considerably lower among those who began to squint at an age of under 1 year, indeed only about $50 \%$. This is no doubt due to the old-fashioned idea that very young infants are too young for diagnosis and treatment. No infant is too young for examination and diagnosis nor for treatment by occlusion (if indicated). In some cases, for instance those of freely alternating squint, the early management may, in the absence of relevant errors of refraction, merely consist in periodic and careful observation. Moreover, the clinician must always bear in mind that a squint may be the outward sign of some serious ocular disease or may be paretic in nature and due to some underlying neurological disorder necessitating further investigation.

It is not always realized that a constant unilateral convergent squint which might otherwise end in a relatively blind eye may, as a result of timely occlusion, become converted into one of freely alternating convergent squint. This will ensure that both eyes keep good vision, and subsequently if the squint is controlled by correction of the refractive error or by surgery and orthoptic treatment or both thr child may attain binocular single vision or, failing that, some useful form of binocular association. The development and preservation of good vision in each eye of a young child is a duty which every ophthalmologist must accept, but in order to discharge this duty he must rely on the early referral of all cases of squint by general practitioners, paediatricians, doctors in infant welfare clinics, health visitors, and others, but perhaps above all on its early recognition by parents and relatives, especially when there is a family history of squint. Delay in diagnosis and treatment is dangerous.

\section{Fall-out and Strontium}

After the explosion of the first hydrogen bomb in 1954 radioactive contamination of the environment and of human tissues reached measurable levels in many parts of the world. The long-term significance of fall-out is linked with deposition of strontium-90, a radioactive isotope with a halflife of 28 years. Because of its chemical affinity with calcium, this material is deposited in the skeleton, where it may be detected by chemical treatment and radioactive assay of bone samples obtained post mortem.

Work of this sort began in Great Britain in $1955^{1}$ and is now conducted by two groups (one at the Capenhurst laboratories of the United Kingdom Atomic Energy Authority and one in Glasgow), who analyse more than 400 bone samples a year. The concentration of strontium- 90 in bone is greater in children than in adults. The level of contamination rose to a peak in 1959 and declined slowly for three years before rising to another maximum in 1964 and 1965. The latest report ${ }^{2}$ from the Medical Research Council, covering the first half of 1966 , shows that levels of strontium90 in bone continue to decline slowly, though remaining higher than at any time before 1964 .

\footnotetext{
1 Bryant, F. J., Chamberlain, A. C., Morgan, A., and Spicer, G. S., Radiostrontium in Soil, Grass, Milk and Bone in the United Kingdom, 1956, Results (A.E.R.E. HP/R 2533). 1957. H.M.S.O. ${ }^{*}$ Medical Research Council Monitoring Report No. 14, Assay of 1966, part 1. 1967. H.M.S.O.
}

Arrangements for the analysis of human bone samples in the United Kingdom have been altered in a small but significant way. Until now the femur has been used in the British programme, but vertebrae have been analysed in most other countries. The difference is not important for infants, children, and adolescents, for whom little variation has been found in strontium-90 levels among the bones of the skeleton. In adults, however, the concentration of strontium-90 in vertebral bone is two to three times greater than in the femur. It has now been decided that the United Kingdom Atomic Energy Authority team (who receive an appreciable number of samples from adult subjects as well as from infants and children) will use vertebrae for analysis. The Glasgow group, whose work is confined mainly to study of samples from subjects under 5 years of age, will continue to analyse femora.

For the present, levels of strontium-90 in human bone do not give cause for serious anxiety in regard to radiation hazards, but valuable information is beginning to emerge from the study of the long series of results now available and from comparisons with other countries, where diet and weather conditions lead to differences in uptake of radioactive fall-out.

\section{Coin - operated Vending Machines}

The coin-operated vending machine answers a demand for quick meals and drinks at any hour of the day or night. Labour is minimal, being required only for maintenance and supplies. The machines are filled by the occupant of the land or premises on which they stand or by the company operating them. They may be either hired or purchased. If hired their maintenance is the responsibility either of the company loaning the machines or of those hiring them. Vending machines may be found in factories, hospitals, offices, and air, rail, or sea terminals, garages, sports grounds, exhibition halls, and also in streets and arcades of towns and cities. The food sold ranges from hot meals and sandwich or pie snacks to hot or cold drinks of many varieties.

The food is stored in an enclosed system, so that a simple cleaning process is essential to avoid the accumulation of stale food, particularly in powdered form, or liquid in parts of the machine invisible to the public eye. Many of the cold foods are perishable-for example, meat sandwiches, pies, and sausage rolls. Thus the temperature of storage is important and also the length of time the foods are held in the machine. The Food Hygiene Code of Practice No. 7, 1 of which $\mathbf{M}$. Parry $^{2}$ has discussed the background, recommends a temperature of storage in accordance with the Food Hygiene Regulations ${ }^{3}$ - that is, below $10^{\circ}$ C. $\left(50^{\circ} \mathrm{F}\right.$.) or above $62^{\circ} \mathrm{C}$. $\left(145^{\circ} \mathrm{F}\right.$.) - though these regulations apply only to food for immediate consumption in catering establishments. The Code of Practice gives no recommended time of storage for perishable products in vending machines, which in fact are acting as domestic refrigerators and should be operated at

\footnotetext{
Hygiene in the Operation of Coin-operated Food Vending Machines, Food Hygiene Code of Practice No. 7, 1967. H.M.S.O. Food Hygiene Code of Practice No. 7, 1967.

2 Parry, M., Publ. Hlth Inspect., 1967, 75, 369. Statutory Instruments (1960), The Food
tions, 1960, Cmnd. 1601. H.M.S.O.

4 Hughes, H. L., Munic. Engng. Lond., 1967, 144, 926.

Skinner, W. E. D., Roy. Soc. Hlth f., 1967, 87, 19.

- Bailey, C. A., Publ. Hlth Inspect., 1967, 75, 306.

7 Gibson, H. G., ibid., 1966, 75, 121.
} 